\title{
A gradual shift in initial foot-to-ground contact patterns depending upon acceleration
}

\author{
Ine Van Caekenberghe ${ }^{\mathrm{a}, \mathrm{b}}$, Philippe Malcolm ${ }^{\mathrm{a}}$, Veerle Segers ${ }^{\mathrm{a}}$, Dirk De Clercq ${ }^{\mathrm{a}}$ \\ ${ }^{\mathrm{a}}$ Department of Movement and Sports Sciences, Ghent University, Belgium \\ ${ }^{b}$ Functional Morphology, Department of Biology, University of Antwerp, Belgium
}

\section{Introduction}

Running involving sub-maximal accelerations occurs very frequently during sports. Insight into the biomechanics of this type of unsteady locomotion therefore is of interest for $e . g$. footwear design and sports training. A net acceleration of the body centre of mass $(\mathrm{BCOM})$ is realized by increasing the net horizontal impulse by proportionally less braking and more propulsion (Van Caekenberghe et al., in press), while controlling total body angular momentum. The increase in net impulse is related to a more anterior ground reaction force (GRF) vector and is accompanied in kinematics by an equally more forward body lean (Kugler and Janshen, 2010). Body lean is quantified as the angle relative to the vertical of a line between the BCOM and the centre of pressure (COP) which can be regarded as a moving pivot-point mechanism, among others determined by its initial contact location on the foot. Maximal accelerations during sprinting are characterized by an active (clawing) touchdown on the forefoot (Johnson and Buckley, 2001). Given the gradual change in force characteristics and body orientation, a gradual change in foot fall patterns towards the touchdown observed during maximal accelerations is expected during sub-maximal accelerations. The location of initial foot to ground contact is hypothesized to shift anteriorly on the foot (change towards forefoot strike (FFS)) with larger accelerations. However, at steady state, interindividual differences in the location of initial foot contact (already) exist. Rearfoot strikers (RFS) have a larger margin of progression to the FFS pattern than midfootstrikers (MFS), as such a larger acceleration effect is expected in the RFS population. Another means of quantifying initial foot contact consists in the foot-toground angle at initial contact, which is hypothesized to enlarge (i.e. toes gradually lower than the heel) as acceleration enlarges.

\section{Purpose of the study}

The aim is to discuss the acceleration effect on the location of initial contact on the foot and on the foot segment angle during sub-maximal running accelerations overground.

\section{Methods}

9 subjects ran on a 30m long runway with 4 force platforms $(1000 \mathrm{~Hz})$ and a $2 \mathrm{~m}$ Footscan (RSscan $\left.{ }^{\circledR}, 500 \mathrm{~Hz}\right)$. 3D kinematics were recorded (Qualisys ${ }^{\circledR}$ ) and analyzed (Visual $3 \mathrm{D}$, C-Motion $($ ). . Per subject $72 \pm 29$ stances were analyzed. Subjects ran at different constant speeds $(2-7 \mathrm{~m} / \mathrm{s})$ and accelerated at sub-maximal accelerations $\left(0-4 \mathrm{~m} / \mathrm{s}^{2}\right)$. A multiple linear regression analysis (independent variables: acceleration and speed (covariate)) was used to determine the acceleration effect on the dependent variables. Acceleration was calculated by means of the GRF. Speed was calculated as the mean speed of the BCOM. Initial foot contact location was determined as the percentage of total foot length at which the COP is starting from the 
heel when the vertical GRF reaches $10 \%$ of the maximal vertical force (i.e., strike index [SI],Williams and Cavanagh, 1987). Foot abduction is taken into account in the calculations. Foot-ground segment angle is the foot angle in the sagittal plane normalized to neutral standing position with a positive angle indicating toes lower than the heel.

\section{Results}

At speeds in between 3 and $4 \mathrm{~m} / \mathrm{s}$ the mean SI of the subjects is $0.29 \pm 0.18$. Based upon this variable, the subjects were divided in a RFS group (5 subjects, SI: $0.15 \pm 0.02$ ) and a MFS group (3 subjects, SI: $0.48 \pm 0.05$ ). In one other subject, RFS and FFS were observed. The acceleration coefficient in the regression indicates the change in SI and foot-ground angle per $1 \mathrm{~m} / \mathrm{s}^{2}$ acceleration rise over the whole speed $(2-7 \mathrm{~m} / \mathrm{s})$ range. Results are given in Table 1.

The foot angle changes from a negative (toes up) towards a positive angle (heel up) when acceleration enlarges.

\section{Discussion and conclusion}

Per $\mathrm{m} / \mathrm{s}^{2}$ rise in sub-maximal acceleration, the footstrike occurs on average $16 \%$ more towards the toes, and the foot segment angle at initial contact enlarges by $\sim 7^{\circ}$. This applies for habitual RFS as well as MFS as acceleration effects do no statistically differ (Mann Whitney U-test, $\mathrm{p}>0.1$ ).
Through their correlations with acceleration, foot fall patterns are also related to a gradual decrease in braking impulse in favor of the propulsive impulse (Van Caekenberghe et al., in press). This however necessitates a more backward rotation of the leg (from hip to ankle) upon contact to align the BCOM to the GRF vector and thus control the total body angular momentum. This backward leg rotation was demonstrated to be related to the active touchdown in maximal sprint accelerations (Hunter et al., 2005). Altogether these changed foot fall patterns probably create a neuromechanical advantage in decreasing braking and enlarging propulsion. Additionally, the gradually shorter COP-path due to the gradually higher SI also relates to a shorter contact time (Van Caekenberghe et al., in press), which has been considered beneficial for sprinting (Wood, 1987).

\section{References}

Hunter, J.P. et al. (2005). J Apll Biomech 2(1), $31-43$

Johnson, M.D. and Buckley, J.G. (2001). J Sport Sci 19(4), 263-272.

Kugler, F. and Janshen, L. (2010). J Biomech, 43(2), 343-348.

Van Caekenberghe, I. et al. (in press). Gait

Posture, http://dx.doi.org/10.1016/j.gaitpost.2012.10.022

Williams, K.R. and Cavanagh, P.R. (1987). J

Appl Physiol 63(3), 1236-1245.

Wood, G.A. (1987). Med Sport Sci 25, 58-71.

Table 1. Acceleration effects on initial foot-to-ground contact patterns

acceleration effect on

\begin{tabular}{|c|c|c|c|c|}
\hline & \multicolumn{2}{|c|}{ strike index } & \multicolumn{2}{|c|}{ initial foot-ground angle } \\
\hline & $\left(\Delta \mathrm{SI} /\left(\mathrm{m} \mathrm{s}^{-2}\right)\right)$ & $\mathrm{R}^{2}$ & $\left(\Delta^{\circ} /\left(\mathrm{m} \mathrm{s}^{-2}\right)\right)$ & $\mathrm{R}^{2}$ \\
\hline & $\mathrm{M} \quad \mathrm{sd}$ & $\mathrm{M}$ & $\mathrm{M} \quad \mathrm{sd}$ & M sd \\
\hline $\operatorname{ALL}(n=9)$ & $0.16 \pm 0.08$ & $0.47 \pm 0.21$ & $6.96 \pm 3.75$ & $0.34 \pm 0.30$ \\
\hline RFS $(n=5)$ & $0.18 \pm 0.09$ & $0.52 \pm 0.26$ & $8.32 \pm 3.06$ & $0.46 \pm 0.30$ \\
\hline MFS $(n=3)$ & $0.15 \pm 0.06$ & $0.43 \pm 0.17$ & $4.69 \pm 4.28$ & $0.14 \pm 0.21$ \\
\hline
\end{tabular}

